\title{
Technical Note-A Comparison of Methods Used to Measure Eating and Ruminating Activity in Confined Dairy Cattle
}

\author{
P. J. Kononoff, H. A. Lehman, and A. J. Heinrichs ${ }^{1}$ \\ Department of Dairy and Animal Science, \\ The Pennsylvania State University, 324 Henning Building, \\ University Park, PA 16802
}

\section{ABSTRACT}

Detailed knowledge of chewing and rumination activities is critical to fully understand the dietary factors affecting normal rumen function. An automatic system for the digital recording of the jaw movements in free-ranging grazing cattle has been described, but its ability to measure chewing activity of cattle housed in confinement and fed total mixed rations has not yet been evaluated. The eating and ruminating behaviors of eight lactating dairy cows were recorded simultaneously by a wireless automatic system and by 5 -min interval observation over 24 -h periods. Results indicated that both methods agreed on identification of eating and ruminating bouts. Mean differences between methods for total time eating ( $8.7 \mathrm{~min} \pm 12.8)$ and ruminating (42.9 min \pm 12.0 ) were significantly different. The time recorded by observation in both eating and rumination was 3.6 and $10.3 \%$ higher compared with the automatic system. Differences indicate inaccuracies in the observational method itself. The automatic system may prove useful in further studies examining eating and rumination activities in cattle. (Key words: eating, ruminating, automatic recording, Graze software)

In ruminants, chewing during eating and rumination functions to reduce feed particle size and to increase particle surface/volume ratio (Poppi and Norton, 1980). An alteration of these physical feedstuff properties results in improved microbial access and feed degradation (McAllister et al., 1994) and facilitates the passage of undigested feed residues out of the rumen (Bernard et al., 2000; and Welch, 1984). Chewing stimulates secretion of saliva, which contains high concentrations of bicarbonate and phosphate buffers and aids in maintaining a rumen $\mathrm{pH}$ level suitable for microbial activity (Beauchemin,

Received September 13, 2001.

Accepted January 14, 2002.

Corresponding author: A. J. Heinrichs; e-mail: ajhs@psu.edu.

${ }^{1}$ Reprint requests.
1991). A variety of methods can quantify chewing activity in dairy cows (Heinrichs and Conrad, 1987; Luginbuhl et al., 1987; Beauchemin et al., 1989; Matsui and Okubo, 1991). For accurate study of chewing behavior, long periods of eating and ruminating activity must be measured using electronic recordings or approximated through visual observation (Penning, 1983). Although data are reported in a similar manner using either method (i.e., $\mathrm{min} / \mathrm{d}$, $\mathrm{min} / \mathrm{kg}$ of DMI, etc.), differences between methods of measurement may exist. The Institute of Grassland and Environmental Research (IGER) Behavior Recorder (Ultra Sound Advice, London, UK) is a system capable of digitally recording jaw movements of free-ranging grazing cattle (Rutter et al., 1997). Because of its compact construction and ability to function without constraint of the animal, the use of this technology may prove convenient and accurate for traditional research in either confined or in loose-stall housing. In spite of its potential use, its ability to detect and identify different jaw movements (eating or ruminating) of nongrazing animals has not yet been validated.

The objective of this study was to compare differences between observational and electronic chewing measurement techniques and to determine the ability of the automatic system to detect and measure eating and ruminating behavior in nongrazing animals.

Eight lactating multiparous Holstein cows $94 \pm 9$ DIM, producing $35 \pm 6 \mathrm{~kg}$ of milk, and a mean BW of $673 \pm 42 \mathrm{~kg}$ were each fitted with an automatic wireless bite recorder for a 24 -h period. All animals were previously fitted with the recorders and were accustomed to wearing them. Cows were housed in individual stalls, milked at 0730 and $1930 \mathrm{~h}$, and fed an alfalfa silage-based TMR at $0800 \mathrm{~h}$ for ad libitum consumption.

The IGER Behavior Recorder system is composed of a sensory noseband and a single board computer (Triangle Digital Services, London, UK) containing a CompactFlash memory card and powered by a rechargeable $7.2 \mathrm{~V}, 1.7 \mathrm{~A}$ h nickel-cadmium battery. Data recorded and stored on the memory card was later analyzed using Microsoft Windows-based soft- 
Table 1. Total time (min) and calculated method differences (min) of ruminating and eating activities as measured by the automatic electronic system and estimated by observation.

\begin{tabular}{|c|c|c|c|c|c|}
\hline & Observed & Electronic & $\begin{array}{l}\text { Method } \\
\text { difference }\end{array}$ & SD & $P$-Value \\
\hline \multicolumn{6}{|l|}{ Eating } \\
\hline No. of bouts/d & 9.4 & 9.5 & 0.1 & 0.4 & 0.35 \\
\hline Total time, $\mathrm{min} / \mathrm{d}$ & 246.9 & 238.1 & 8.8 & 12.8 & 0.09 \\
\hline Time/bout (min) & 27.9 & 26.0 & 1.9 & 2.6 & 0.08 \\
\hline \multicolumn{6}{|l|}{ Ruminating } \\
\hline No. of bouts/d & 14.3 & 14.5 & 0.2 & 0.5 & 0.17 \\
\hline Total time, $\mathrm{min} / \mathrm{d}$ & 415.0 & 372.1 & 42.9 & 12.0 & $<0.01$ \\
\hline Time/bout (min) & 29.6 & 26.0 & 3.6 & 1.6 & $<0.01$ \\
\hline
\end{tabular}

ware program "Graze" (Rutter et al., 1997). The program displays a plot of the signal amplitude against time and automatically identifies eating, ruminating, and resting behavior through induction of amplitude, frequency, and shape of the jaw movements (Rutter, 2000).

The Graze software automatically identifies different jaw movements as either ruminating or eating but may occasionally misinterpret the activity. This is corrected by manual review as ruminating behavior is easily identified as the regular pattern and amplitude characterized with a 5 - to 10 -s period between boli when no jaw movements occur. Chewing activities were also estimated concurrently through a visual observation method at 5-min intervals. The total number of minutes eating, ruminating, and resting activity were then estimated by the sum of each observation and multiplied by a factor of five (Shaver et al., 1988). Because of difficulties observing the animals out of the stall, activities were not recorded at the time of milking or during movement to the milking parlor (approximately $2 \mathrm{~h} / \mathrm{d}$ ).

Computer records of chewing activity were evaluated to determine whether the electronic method agreed with observational data at each 5-min interval. Assuming a method difference in ruminating activity of $40 \mathrm{~min}$ and a SD of 10 a test consisting of eight observations would maintain $>90 \%$ statistical power. Total eating and ruminating time was calculated in minutes, and a paired sample $t$ test was used to determine whether differences in measured and estimated total time eating and ruminating were significant (Steel et al., 1997). Statistical calculations for the paired sample $t$ test were carried out using the PROC UNIVARIATE procedure of the SAS, Version 8.1.

On average, both total chewing time and average bout length tended to be higher using the observational method (Table 1). Total time ruminating was higher using the observational method in all eight observations. Total time eating was higher using the observational method in all but two observations, where differences were minimal. Mean method differences for total time eating $(8.7 \mathrm{~min} \pm 12.8)$ and total time ruminating (42.9 min \pm 12.0 ) were significant. Because the observational method is a representation of activity occurring at 5-min intervals and not continuous as in the electronic measurement, differences between methods most likely indicate inaccuracies in the observational measurement and its ability to detect the exact start and finish of each chewing bout. The results of this experiment indicate that absolute values of chewing activities between experiments should not be directly compared when method of estimation is different.

\section{ACKNOWLEGMENTS}

This research was supported in part by USDA grant no. 97-34281-4590 and was a component of NC-119, Dairy Herd Management Strategies For Improving Decision Making and Profitability. The authors would like to thank M. Long, T. Ross, A. Hess, K. Harvatine, N. Saloman, and S. Rodriguez for their assistance with experimental observation.

\section{REFERENCES}

Beauchemin, K. A. 1991. Ingestion and mastication of feed by dairy cattle. Vet. Clin. North Am. Food Anim. Pract. 7:439-462.

Beauchemin, K. A., S. Zelin, D. Genner, and J. G. Buchanan-Smith. 1989. An automatic system for quantification of eating and ruminating activities of dairy cattle housed in stalls. J. Dairy Sci. 72:2746-2759.

Bernard, L., J. P. Chaise, R. Baumont, and C. Poncet. 2000. The effect of physical form of orchardgrass hay on the passage of particulate matter through the rumen of sheep. J. Anim. Sci. 78:1338-1354.

Heinrichs, A. J., and H. R. Conrad. 1987. Measuring feed intake patterns and meal size of lactating dairy cattle. J. Dairy Sci. 70:705-711.

Luginbuhl, J. M., K. R. Pond, J. C. Russ, and J. C. Burns. 1987. A simple electronic device and computer interface system for monitoring chewing behavior of stall-fed ruminant animals. J. Dairy Sci. 70:1307-1312.

Matsui, K., and T. Okubo. 1991. A method for quantification of jaw movements suitable for use on free ranging cattle. Appl. Anim. Behav. Sci. 32:107-116. 
McAllister, T. A., H. D. Bae, G. A. Jones, and K. J. Cheng. 1994. Microbial attachment and feed digestion in the rumen. J. Anim. Sci. 72:3004-3018.

Penning, P.D. 1983. A technique to record automatically some aspects of grazing and ruminating behavior in sheep. Grass Forage Sci. 38:89-96.

Poppi, D. P., and B. W. Norton. 1980. The validity of the critical size theory for particles leaving the rumen. J. Agric. Sci. Camb. 94:275-280.

Rutter, S. M. 2000. Graze: a program to analyze recordings of the jaw movements of ruminants. Behav. Res. Meth. Inst. Comp. 32:86-92.
Rutter, S. M., R. A. Champion, and P. D. Penning. 1997. An automatic system to record foraging behavior in free-ranging ruminants. Appl. Anim. Behav. Sci. 54:185-195.

Shaver, R. D., A. J. Nyted, L. D. Satter, and N. A. Jorgensen. 1988. Influence of feed intake, forage physical form, and fiber content on particle size of masticated forage, ruminal digesta and feces of dairy cows. J. Dairy Sci. 71:1566-1572.

Steel, R. G., J. H. Torrie, and D. Dickey. 1997. Principles and Procedures of Statistics, a Biometrical Approach. The McGraw-Hill Co., Inc. New York.

Welch, J. G. 1984. Rumination, particle size and passage from the rumen. 1984. J. Anim. Sci. 54:885-894. 